\title{
Why are you strategizing? Response to "Eleven strategies for getting into graduate school in ecology \& evolutionary biology"
}

\author{
Catherine A. Dale \\ Catherine A. Dale (9cad@queensu.ca), Department of Biology, Queen's University, Kingston ON, K7L 3N6 Canada
}

In his paper Eleven strategies for getting into graduate school in ecology \& evolutionary biology, Walters (2018) offers some practical and well-considered advice for prospective graduate students, based on his 25 years of experience in academia. I agree with most of Walters' suggestions, and I think his recommendations are valuable for any undergraduate who wants to continue his or her studies in biology.

However, I would like to offer some complementary advice from a different perspective. As a recent $\mathrm{PhD}$ graduate in ecology and evolutionary biology, my advice would be to take a moment to think before you begin strategizing to get into grad school. Stop for a moment and seriously ask yourself this question: "Why do I want to go to grad school?"

Many undergraduates consider a graduate degree a necessary step towards achieving the type of job they want. This may be true in some cases, particularly of a Master's degree. Holding a Master's may help your resume stand out to prospective employers, land you a higher starting salary, or allow you to rise faster through the ranks once employed (Murray 2017). However, getting a Master's can also come with some disadvantages, since you are likely to have less actual experience when applying for a job-and perhaps inflated expectations for salary and responsibilities as well (Dehaas 2013). In fact, according to data from the National Household Survey, in 2011, Canadians 25 to 44 with a Master's degree had a higher unemployment rate (5.7\%) than those with Bachelor's degrees (4.8\%; Dehaas 2013).

So the jury is still out on whether a Master's degree enhances your job prospects. But even if it does, a $\mathrm{PhD}$ probably doesn't. Most jobs don't require a $\mathrm{PhD}$, and having one may make you 'overqualified' for a position, at least in the eyes of those doing the hiring. The exception, of course, is the position of tenure-track university faculty member. But if that's your intended path, the news isn't great.

Many - perhaps even most — students begin their PhD with the intention of pursuing a career in academia. However, the simple fact is that institutions are producing more $\mathrm{PhD}$ graduates than there are faculty positions available (Larson et al. 2014, Kolata 2016). In the U.S., for example, data collected by the National Science Foundation in 2011 indicates that only $9.4 \%$ of $\mathrm{PhD}$ graduates in the life sciences had secured academic jobs at graduation (Weissmann 2013).

Ecology and evolutionary biology is no exception: like most other disciplines, the field of biology has "many more PhDs than academic posts" (Kolata 2016). For anyone pursuing - or even considering pursuing - a graduate degree in biology, these reports don't make easy reading. To be honest, even though they aren't telling me anything I don't already know from personal experience, reading the grim facts makes me wince every time. But I would suggest it's worth making yourself face these realities before launching into a $\mathrm{PhD}$. It's very easy at the beginning of your graduate studies to convince yourself that you will be in that small percentage that land their academic dream jobs. But the fact is, the majority of us will not.

On top of that, there's no denying that graduate school can be a tough road to walk. Financial stress, feelings of inadequacy, and social isolation are all part of the package. Unsurprisingly, this can lead to mental health issues. In fact, a recent study published in Nature Biotechnology found that graduate students are six times more likely than the general population to experience depression and anxiety (Evans et al. 2018).

Despite all that, I'll be honest: I don't regret my decision to pursue a PhD. And that's true even though I'm not a member of that lucky minority who have 
achieved a tenure-track professorship. Doing my $\mathrm{PhD}$ certainly wasn't the easiest or perhaps even the smartest path I could have chosen. Finishing my thesis was a lengthy, painful struggle, and there were many days where I seriously considered giving up. But ultimately, doing my $\mathrm{PhD}$ gave me the opportunity to spend several years engaged in scientific research - and I don't know whether I'll have that opportunity again now that I've joined the workforce.

And so my advice is this. If your interest in graduate school is all about the destination - that is, what having a graduate degree will get you-then I'd suggest that careful research into job prospects and the requirements of your potential career is in order. Based on this research, you can make an educated decision about whether going to grad school will help get you where you want to be.

If, however, your interest is in the journey itself, then by all means go to grad school. Just keep in mind that you may not end up where you initially thought you were heading.

\section{References}

Dehass, Josh. 2013. Master's degrees don't mean more job offers: an expert's advice on when to stop at a bachelor's. Macleans. Accessed 9 September 2018. https://www.macleans.ca/work/jobs/mastersdegrees-dont-mean-more-job-offers/.

Evans, Teresa M., Lindsay Bira, Jazmin Beltran Gastelum, L. Todd Weiss, and Nathan L. Vanderford. 2018. Evidence for a mental health crisis in graduate education. Nature Biotechnology 36: 282-284.

Kolata, Gina. 2016. So many research scientists, so few openings as professors. The New York Times. Accessed 9 September 2018. https://www.nytimes .com/2016/07/14/upshot/so-many-researchscientists-so-few-openings-as-professors.html.

Larson, Richard C., Navid Ghaffarzadegan, and Yi Xue. 2014. Too many PhD graduates or too few academic job openings: the basic reproductive number $R_{0}$ in academia. Systems Research and Behavioral Science 31: 745-750.

Murray, Seb. 2017. Will a master's give the edge in your career? The Guardian. Accessed 9 September 2018. https://www.theguardian.com/education/2017/nov/1 0/wo-degrees-better-than-one-career-prospectspostgraduate-students.

Walters, E.L. 2018. Eleven strategies for getting into graduate school in ecology \& evolutionary biology. Ideas in Ecology and Evolution 11: 78-83. CrossRef

Weissmann, Jordan. 2013. How many Ph.D.'s actually get to become college professors? The Atlantic. Accessed 9 September 2018. https://www.theatlantic .com/business/archive/2013/02/how-many-phdsactually-get-to-become-college-professors/273434/. 